\title{
Home Ranges and Spatial Organization of Fishers, Martes pennanti, in Central British Columbia
}

\author{
Richard D. Weir ${ }^{1}$, Alton S. HarestaD ${ }^{2}$, and Fraser B. Corbould ${ }^{3}$ \\ ${ }^{1}$ Artemis Wildlife Consultants, 4515 Hullcar Road, Armstrong, British Columbia, Canada V0E 1B4; e-mail: rweir@artemis \\ wildlife.com \\ ${ }^{2}$ Department of Biological Sciences, Simon Fraser University, Burnaby, British Columbia, Canada V5A 1S6 \\ ${ }^{3}$ Peace/Williston Fish and Wildlife Compensation Program, Suite 325, 1011 Fourth Avenue, Prince George, British Columbia, \\ Canada V2L $3 \mathrm{H} 9$
}

Weir, Richard D., Alton S. Harestad, and Fraser B. Corbould. 2009. Home ranges and spatial organization of Fishers, Martes pennanti, in central British Columbia. Canadian Field-Naturalist 123(2): 126-132.

We described the size and spatial arrangement of aggregate and seasonal home ranges for 17 radio-tagged resident Fishers (Martes pennanti) that were $>1.5$ years old in two areas of central British Columbia during 1990-1993 and 1996-2000. We estimated home range size for each Fisher from the $95 \%$ isopleth of the utilization distribution generated using a fixed kernel model with smoothing selected by least-squares cross-validation (95\% FK). For comparison to previous studies, we also calculated the minimum convex polygon estimate of home range size (MCP) for each animal. The aggregate home ranges $(95 \% \mathrm{FK})$ of female Fishers $\left(\bar{x}=37.9 \mathrm{~km}^{2}, \mathrm{SD}=18.5\right.$, range $\left.=10.5-81.2, n=11\right)$ were significantly smaller than those of males $\left(\bar{x}=161.3 \mathrm{~km}^{2}, \mathrm{SD}=100.0\right.$, range $\left.=46.0-225.2, n=3 ; P=0.019\right)$. We observed minor overlap among $95 \%$ FK home ranges of Fishers of the same sex, but considerable overlap among home ranges of males and females. Home ranges (95\% FK or MCP) that we observed in central British Columbia were larger than those reported elsewhere in North America, particularly for males. We suggest that the distribution of resources for Fishers may occur at lower gross densities in central British Columbia than in other portions of the Fisher's range and that suitable habitat in which Fishers can establish home ranges is not found uniformly across the landscape.

Key Words: Fishers, Martes pennanti, home range, spatial organization, British Columbia.

Fishers are solitary carnivores and, other than mothers raising their young, adults interact with conspecifics usually only during mating and territorial defence (Powell 1993). Fishers are aggressive and conspecific interactions often lead to fights that are occasionally fatal (Powell 1993). The asociality of Fishers is also exhibited in their spatial organization. Fishers exhibit intrasexually exclusive home ranges, a common spacing pattern among the Mustelidae in which territories of members of the same sex rarely overlap (Kelly 1977; Powell 1979; Arthur et al. 1989).

Differential selection between the sexes in Mustelidae has resulted in different strategies of space use for each sex and, consequently, the spatial organization of the population. Moors (1980) hypothesized that male mustelids are larger than females so that they can cover large areas more quickly, and therefore encounter more females as potential mates, whereas the smaller size of females optimizes prey capture during rearing of the young (Powell 1993). To sequester sufficient resources and meet the greater energy demands of increased size, males have larger home ranges than females. This spatial organization, in combination with the size of the home range, has implications for the density of Fishers that occupy a landscape.

Powell (1994) summarized the reported sizes of home ranges of Fishers from across North America and derived a mean home range size of $15 \mathrm{~km}^{2}$ for females and $38 \mathrm{~km}^{2}$ for males, but found regional variation.
Estimates of home range sizes from Idaho and Montana suggest that the home range sizes of Fishers are larger in western regions than in eastern and southern areas possibly because of lower densities of prey (Idaho, Jones 1991; Montana, Heinemeyer 1993). Badry et al. (1997) found that translocated Fishers in Alberta had home ranges of $14.9 \mathrm{~km}^{2}$ and $24.3 \mathrm{~km}^{2}$ for females (F) and males (M) respectively, which were slightly larger home ranges than those reported for Fishers in eastern North America (e.g., Maine, $16.3 \mathrm{~km}^{2}$ (F), $30.9 \mathrm{~km}^{2}(\mathrm{M})$, Arthur et al. 1989; Massachusetts, 7.6 $\mathrm{km}^{2}(\mathrm{~F}), 10.0 \mathrm{~km}^{2}(\mathrm{M})$, Fuller et al. 2001; Quebec: $5.4 \mathrm{~km}^{2}(\mathrm{~F}), 9.2 \mathrm{~km}^{2}(\mathrm{M})$, Garant and Crête 1997).

Few studies have examined the spatial organization of Fishers in the northern half of their distribution and little is known about the sizes of home ranges of Fishers in these areas. The objectives of our study were to describe the spatial organization of Fishers and to examine effects of season and sex on space use in central British Columbia. We expect that the spatial organization and home range size of Fishers in British Columbia may differ from elsewhere because of possible differences in densities and distributions of resources, such as food or specific habitats, for Fishers. This information will be useful in estimating population densities for the Sub-Boreal Spruce Biogeoclimatic zone (Meidinger et al. 1991) and help managers determine the status of Fishers in central British Columbia. 


\section{Study Areas}

Our $1830-\mathrm{km}^{2}$ northern study area (Williston) was centred $220 \mathrm{~km}$ north of Prince George, British Columbia $\left(54^{\circ} 1^{\prime} \mathrm{N}, 122^{\circ} 47^{\prime} \mathrm{W}\right)$ and lied within the moist-cool and wet-cool subzones of the Sub-Boreal Spruce Biogeoclimatic (SBS) zone to the west of the Williston Reservoir. Our 1,500-km² southern study area (Beaver Valley) lied $200 \mathrm{~km}$ south of Prince George entirely within the dry-warm subzone of the SBS zone. The SBS zone is a heavily forested, coniferous, montane zone dominating the landscape of the central interior of British Columbia and generally occurs from valley bottoms to about $1300 \mathrm{~m}$ above sea level (Meidinger et al. 1991). The climate of the SBS zone is continental and characterized by severe, snowy winters and relatively warm, moist, and short summers. Both study areas were ecologically similar: the Beaver Valley area received $536 \mathrm{~mm}$ of precipitation per year and had a mean annual temperature of $3.6^{\circ} \mathrm{C}$ (Steen and Coupé 1997); the moist-cool subzone in the Williston area received $690 \mathrm{~mm}$ of precipitation and had a mean annual temperature of $1.2^{\circ} \mathrm{C}$ (MacKinnon et al. 1990). Both of our study areas were selected, in part, because Fisher populations were low in these regions and the species was of conservation concern.

Forests in both study areas were dominated by Lodgepole Pine (Pinus contorta var. latifolia) and hybrid White Spruce (Picea engelmannii $\times$ glauca), with minor deciduous components of Trembling Aspen (Populus tremuloides), Paper Birch (Betula papyrifera), and Black Cottonwood (Populus balsamifera trichocarpa). Douglas-fir (Pseudotsuga menziesii var. glauca) was a common mid- to late-successional species in the Beaver Valley study area, whereas Subalpine Fir (Abies lasiocarpa) was found primarily in older stands in the Williston study area. Common understory shrubs were Prickly Rose (Rosa acicularis), Black Huckleberry (Vaccinium membranaceum), Black Twinberry (Lonicera involucrata), Kinnikinnick (Arctostaphylos uva-ursi), and Black Gooseberry (Ribes lacustre).

The dry and moist subzones of the SBS had a natural disturbance regime of frequent, large-scale fires on a cycle of about 150 years, with most stands burning every 100 years, while the wet subzone had typical fire return intervals of greater than 250 years (British Columbia Ministry of Forests and British Columbia Ministry of Environment, Lands and Parks 1995). Forest harvesting, using a variety of techniques, had occurred over the past 40 years and created a mosaic of seral stages and stand types throughout the study areas. The entire Williston study area was forested, with no permanent human developments. Land clearing for cultivation and cattle grazing occurred extensively along most valley bottoms in the Beaver Valley study area, but accounted for less than $5 \%$ of the land base. Harvesting of Fishers for fur was very low in both study areas with between none and three harvested by trappers per year in each study area.

\section{Methods}

We live-trapped, radio-tagged, and monitored Fishers as part of two larger studies on the ecology of Fishers in British Columbia (Weir and Harestad 2003; Weir and Corbould 2006). We assumed that we captured and radio-tagged each resident Fisher in each study area because we intensively live-trapped each study area for Fishers during winter, conducting 3540 trapnights of live-trapping effort in the Beaver Valley area and 9234 trapnights in the Williston area. We monitored Fishers during 1990-1993 in the Beaver Valley study area and during 1996-2000 in the Williston study area. We removed a premolar 1 tooth for cementum annuli analysis (Strickland et al. 1982) from healthy Fishers to determine their year of birth. For individuals for which we were unable to extract a tooth, we classed Fishers as adults or juvenile by palpating the saggital crest and examining tooth wear (Powell 1993).

We located Fishers using standard ground and aerial telemetry procedures (White and Garrott 1990). From the ground, we recorded directional bearings from permanent ground stations to Fishers using a three-element, collapsible Yagi antenna. We estimated radiolocations and $95 \%$ error polygons from ground telemetry using the maximum likelihood estimator (Locate II software; Nams 1990). For home range analysis, we included only those radiolocations that had $95 \%$ error polygons smaller than $0.75 \mathrm{~km}^{2}$. We observed average maximum movement rates of 728 $\mathrm{m} / \mathrm{h}$ for females $(\mathrm{SD}=812, n=11)$ and $873 \mathrm{~m} / \mathrm{h}$ for males $(\mathrm{SD}=379, n=3)$. Based upon this empirical data and approximated home range sizes of $35 \mathrm{~km}^{2}$ for females and $160 \mathrm{~km}^{2}$ for males, we considered that a female Fisher could reach any point within its home range within 9.2 hours and males could do so within 16.3 hours. Thus, to be slightly conservative, we considered radiolocations to be temporally independent if separated by $>18$ hours for either sex.

All of the Fishers radio-tagged in the Williston study area were resident individuals. Fifteen fishers (13 females, two males) were radio-collared and translocated into the Beaver Valley study area during two winters (Weir 1995). All of these Fishers were captured from ecologically similar areas (SBS and Sub-Boreal Pine Spruce biogeoclimatic zones) in the Chilcotin region $\left(52^{\circ} 30^{\prime} \mathrm{N}, 124^{\circ} 38^{\prime} \mathrm{W}\right)$ and translocated into areas that were devoid of resident or transient Fishers (as determined by live-trapping). Home ranges were considered to be established for translocated animals when the mean squared distance of a set of six successive locations stabilized and no locations were made outside of the MCP of subsequent 
TABLE 1. Sizes $\left(\mathrm{km}^{2}\right)$ of aggregate and seasonal home ranges and core areas of radio-tagged Fishers in the Sub-Boreal Spruce Biogeoclimatic zone of central British Columbia, 1990-1993 and 1996-2000. Female home ranges denoted with an asterisk are significantly smaller than male home ranges $(P \leq 0.05)$.

\begin{tabular}{|c|c|c|c|c|c|c|c|c|}
\hline & \multicolumn{3}{|c|}{ Male } & \multirow[b]{2}{*}{$n$} & \multicolumn{4}{|c|}{ Female } \\
\hline & $\bar{x}$ & SD & Range & & $\bar{x}$ & SD & Range & $n$ \\
\hline \multicolumn{9}{|l|}{ Aggregate } \\
\hline $95 \% \mathrm{UD}^{\mathrm{a}}$ & 161.3 & 100.0 & $46.0-225.2$ & 3 & $37.9 *$ & 18.5 & $10.5-81.2$ & 11 \\
\hline $\mathrm{MCP}^{\mathrm{b}}$ & 144.2 & 57.6 & $77.7-177.8$ & 3 & $52.6 *$ & 32.0 & $12.0-105.8$ & 11 \\
\hline Core area ${ }^{c}$ & 32.9 & 29.6 & $4.8-63.9$ & 3 & 5.1 & 3.6 & $1.2-13.7$ & 11 \\
\hline \multicolumn{9}{|l|}{ Non-winter ${ }^{\mathrm{d}}$} \\
\hline $95 \%$ UD & 199.5 & 1.4 & $198.4-200.5$ & 2 & 30.8 & 20.5 & $12.2-78.2$ & 11 \\
\hline Core area & 40.4 & 21.9 & $24.9-55.9$ & 2 & 4.4 & 3.0 & $1.8-10.8$ & 11 \\
\hline \multicolumn{9}{|l|}{ Winter $^{\mathrm{d}}$} \\
\hline $95 \%$ UD & 189.7 & & & 1 & 51.2 & 23.9 & $16.1-87.8$ & 7 \\
\hline Core area & 30.4 & & & 1 & 7.0 & 4.4 & $1.1-13.5$ & 7 \\
\hline
\end{tabular}

a $95 \%$ fixed kernel utilization distribution.

${ }^{\mathrm{b}}$ Minimum convex polygon method.

c $50 \%$ fixed kernel utilization distribution.

${ }^{\mathrm{d}}$ Non-winter: 1 April to 14 November; winter: 15 November to 31 March.

observations used by the fisher from May-December (Weir 1995). Nine of these translocated Fishers established home ranges while in radio contact.

We estimated size and location of the home range of each resident adult (i.e., $>1.5$ years old) Fisher using two estimators. For Fishers with 30 or more radiolocations (Seaman et al. 1999), we estimated home ranges using the $95 \%$ isopleth of the utilisation distribution (UD) generated from the fixed kernel method with the smoothing parameter selected by least-squares cross-validation (Worton 1989). For Fishers with repeated observations at one location (i.e., natal or maternal den, rest site), we initially estimated the smoothing parameter for the fixed kernel for a dataset without the repeated observations. Using this value of the smoothing parameter, we re-ran the fixed kernel on the complete dataset. We calculated the core area of each home range using the $50 \%$ isopleth of the same distribution. To allow comparison with other studies, we also calculated aggregate home ranges using the minimum convex polygon (MCP) created from $100 \%$ of the radiolocations obtained for each Fisher. We used the Animal Movement 2.0 script for ArcView 3.x (Hooge and Eichenlaub 1999) for all home range calculations.

We classified each radiolocation into one of two seasons for estimation of seasonal home ranges. We defined the seasons as winter (15 November to 31 March) and non-winter (1 April to 14 November: includes rearing, which begins 1 April [Weir 1995]). We calculated aggregate and seasonal home ranges for each Fisher. For Fishers that we monitored for less than 1.5 seasons (i.e., <275 days), we calculated seasonal home ranges only. For those that were monitored for $>1.5$ seasons, we calculated seasonal and aggregate home ranges. We pooled radiolocations across years for each Fisher for the calculation of their aggregate home range. We estimated seasonal home ranges from data collected within one season (across multiple years) for each Fisher.

We examined differences between sexes for the size of the $95 \%$ and $50 \%$ UD estimates of entire home ranges using a Mann-Whitney U-test. We investigated changes in the sizes of individual 95\% UD home ranges and core areas between winter and non-winter seasons using a Wilcoxon signed rank test. We set the acceptable Type I error at 0.05 .

\section{Results}

We estimated entire, non-winter, and winter home ranges and core areas for 17 adult Fishers in the two study areas: seven Fishers (six females, one male; five translocated into area) in the Beaver Valley study area and 11 Fishers (nine females, two males) in the Williston study area. We collected between 30 and 187 radio locations for each animal $(\bar{x}=57, \mathrm{SD}=40, n=17)$.

\section{Aggregate Home Range}

Aggregate 95\% UD home ranges of female Fishers $\left(\bar{x}=37.9 \mathrm{~km}^{2}, \mathrm{SD}=18.5, n=11\right)$ were significantly smaller than those of males $\left(\bar{x}=161.3 \mathrm{~km}^{2}, \mathrm{SD}=100.0\right.$, $n=3 ; U_{3,11}=30, P=0.038$; Table 1$)$. Estimates of home range area were not strongly correlated to number of radiolocations for either females (slope $=-0.06$, $r^{2}=0.02$ ) or males (slope $\left.=0.94, r^{2}=0.04\right)$. Estimates of the aggregate MCP home ranges were also significantly smaller for females $\left(\bar{x}=52.6 \mathrm{~km}^{2}, \mathrm{SD}=32.0\right.$, $n=11)$ than males $\left(\bar{x}=144.2 \mathrm{~km}^{2}, \mathrm{SD}=57.6, n=3\right.$, $\left.U_{3,11}=30, P=0.038\right)$. Aggregate core areas of females $\left(\bar{x}=5.1 \mathrm{~km}^{2}, \mathrm{SD}=3.6, n=11\right)$ were smaller, but not significantly, than those of males $\left(\bar{x}=32.9 \mathrm{~km}^{2}\right.$, 
$\left.\mathrm{SD}=29.6, n=3, U_{3,11}=29, P=0.060\right)$. Aggregate 95\% UD home ranges of females were significantly smaller in the southern (Beaver Valley) study area $\left(\bar{x}=24.4 \mathrm{~km}^{2}, \mathrm{SD}=10.2, n=5\right)$ than the northern (Williston) study area $\left(\bar{x}=49.1 \mathrm{~km}^{2}, \mathrm{SD}=16.3, n=6\right.$; $\left.U_{5,6}=30, P=0.004\right)$. In both study areas, home ranges were not uniformly spread across the landscape (Figure 1).

\section{Seasonal Home Range}

The mean size of seasonal home ranges for females was $30.8 \mathrm{~km}^{2}(\mathrm{SD}=20.5, n=11)$ during nonwinter and $51.2 \mathrm{~km}^{2}(\mathrm{SD}=23.9, n=7)$ during winter. The average size of the seasonal home range for males was $199.5 \mathrm{~km}^{2}(\mathrm{SD}=1.4, n=2)$ during non-winter and $189.7 \mathrm{~km}^{2}$ for 1 male during winter. We did not detect any significant pair-wise differences for female fishers between winter and non-winter 95\% UD home ranges $(T=2, n=6, P=0.10)$ or core areas $(T=2$, $n=6, P=0.10)$.

\section{Home Range Overlap}

Female home ranges were generally exclusive to other females in Williston study area but less so in the Beaver Valley study area (Figure 1). In the Beaver Valley study area, the home range of one adult female (F002) was almost entirely overlapped by the home ranges of two other adult females (F006, F007), all three of which were translocated animals. Male home ranges were exclusive to other males but overlapped between one and three female home ranges in both study areas.

Overlap of home ranges among female Fishers diminished considerably when we examined core areas. In the Williston study area, we did not observe any overlap among the core areas of the females. In the Beaver Valley study area, however, approximately $40 \%$ of the core areas of F006 and F007 overlapped. Also, a small proportion of the core area of F002 overlapped with the core areas of either F006 or F007.

\section{Discussion}

Generally, Fishers in central British Columbia exhibited the same spatial organization that is found elsewhere in North America. The home ranges of males overlapped extensively with females and home ranges of females tended to be relatively exclusive of other females. However, the sizes and positioning of home ranges across the landscape in our study were substantially different than reported in other studies of Fishers.

The home ranges of fishers in central British Columbia were considerably larger than those recorded elsewhere in their range. Aggregate home ranges for female fishers in our study were up to 10 times larger than those reported by other researchers (e.g., $3.6 \mathrm{~km}^{2}$, Ontario, Koen et al 2007). The aggregate MCP home ranges of male Fishers in our study were up to 15 times the size estimated in other regions (e.g., $9.2 \mathrm{~km}^{2}$,
Québec, Garant and Crête 1997; 30.9 km², Maine, Arthur et al. 1989) and were larger than any other estimate that we encountered in the literature.

The large home range sizes we observed in our study may be related to the density and distribution of resources available to Fishers. In areas with a paucity of prey, we expect home ranges would generally be larger than in areas with abundant prey (Harestad and Bunnell 1979). Thompson and Colgan (1987) found that home ranges of American Martens (Martes americana) in Ontario increased in size as the density of prey declined. Jones (1991) speculated that male Fishers in Idaho had large home ranges because of low prey density. Similarly, Garant and Crête (1997) hypothesized that the home ranges of Fishers in western Québec were very small because of abundant prey. Other researchers have suspected that the availability of prey for Fishers diminishes with increasing latitude, which would result in increased size of the home range (e.g., Buskirk and McDonald 1989). Indeed, home ranges of females in our northern (Williston) study area were larger than those in the Beaver Valley study area, $390 \mathrm{~km}$ to the south. Unfortunately, we did not assess the availability of prey so we were unable to examine the relationship between home range size and prey availability.

Prey may not be the only resource that affected the size of the home ranges of Fishers in our study. Both study areas have been subjected to considerable habitat modification through timber harvesting. Many of the life requisites of Fishers in central British Columbia appear to be linked with riparian habitats (Weir 1995), so hydro-electric flooding and possibly intensive agriculture have removed substantial portions of these habitats from the land base. Habitat alterations are likely cumulative and have changed the distribution and abundance of both prey and important habitat components across the two study areas. These changes to primary resources used by Fishers likely contributed to the spatial organization that we observed.

For sexually dimorphic carnivores such as Fishers, differences in the sizes of home ranges between sexes should be similar to differences in body mass, especially at high densities (Garant and Crête 1997). Aggregate home ranges of male Fishers in our study were 3.9 times the size of female home ranges, while male body mass was only 1.7 times that of females (R. D. Weir, unpublished data). This discrepancy in relative home range size was substantially greater than that reported for Fishers in other areas (1.5, New Hampshire, Kelly 1977; 1.9, Maine, Arthur et al. 1989; 1.8, Québec, Garant and Crête 1997).

This large discrepancy may be linked to the composition of the landscape. Many studies on the ecology of Fishers typically occur in areas with relatively high densities of Fishers (e.g., Arthur et al. 1989; Garant and Crête 1997), possibly because Fishers may be more easily captured in these areas than in areas with 
low densities. In areas where home ranges of females are densely packed and resources are distributed relatively uniformly across the landscape, the ratio of home range size between the sexes appears to be closer to that predicted from body mass ratios (e.g., Garant and Crête 1997). However, in regions with sparse populations of Fishers, females may have large home ranges that are widely dispersed because resources (e.g., prey or habitat) are more rare and the distribution of areas suitable for establishing home ranges may be less uniformly distributed across the landscape. The resultant distribution would be large home ranges with considerable unused areas amongst them, such as the pattern we observed in central British Columbia, where the density of Fishers is among the lowest recorded in the literature (Weir and Corbould 2006).

Home ranges of male Fishers are larger than females because males space themselves to provide mating opportunities with several females (Powell 1994). Thus, male home ranges must be larger to find females as well as sufficient food. The more widely dispersed females and food are distributed, the larger the home range would be expected for males.

Landscape quality, which affects the distribution of resources, affects the density and arrangement of female Fishers in a population. Consequently, landscape quality indirectly affects the distribution and arrangement of males as well. We assume that, for an animal with intrasexually exclusive home ranges such as Fishers, the increase in the discrepancy between body mass ratio and home range size ratio between the sexes is indicative of landscape quality. Thus, we hypothesize that the quality of the landscape for Fishers in central British Columbia is poor relative to other regions of North America.

The differences in the degree of overlap that we noted amongst home ranges of females in the Beaver Valley study area and the Williston study area may have been caused by differences in the distribution of resources between the two areas. In the model proposed by Powell (1994), intrasexually exclusive home ranges are beneficial only at moderate levels of resource availability. When the density of a resource that affects spatial organization (e.g., food) reaches either high or low density, the cost of territoriality is greater than the benefit of exclusive use of the resource and animals will have extensive home range overlap.

The overlap of the core areas that we observed among the 3 females in the Beaver Valley study may have occurred because of a relatively high density of prey in the areas of overlap. During winter track surveys, we noted that the area of overlap had a very high density of Snowshoe Hares (Lepus americanus) and microtines (R. D. Weir, unpublished data) compared to elsewhere in our Beaver Valley study area. This area was unique because of the high volume of coarse woody debris, dense Douglas-fir regeneration, and relatively wet moisture regime; all habitat features that are positively correlated with prey of Fishers. By contrast, other portions of the Beaver Valley study area and the Williston study area had much lower densities of these habitat features.

Our failure to detect changes in home range size among seasons may have been caused by several factors. Although non-winter home ranges were substantially smaller than winter home ranges for five of six females, our sample sizes were small, thus we may not have had sufficient statistical power to determine if a difference did exist. Second, a substantial difference may not exist between winter and non-winter home ranges of Fishers in our study areas. Lastly, we consolidated seasonal radiolocations from as many as three consecutive years for some females because of constraints of sample size. As shown by Arthur et al. (1989) in Maine, areas used by female Fishers vary among years. If the Fishers in our study were using distinct portions of their home range in each year, this effect would be ameliorated by our methods.

Fishers appear to occur at very low densities in portions of the Sub-Boreal Spruce Biogeoclimatic zone (Weir and Corbould 2006), despite this zone being considered among the most productive zones for Fishers in the province (Banci 1989). The Fisher density in central British Columbia is likely affected by the large home range sizes and little overlap amongst home ranges of the same sex.

Alteration of the landscape, which influences the distribution of potential home ranges, will inevitably affect the density of the Fisher population. Our findings suggest that Fishers are not distributed uniformly across the landscape and home ranges may be large because of the dispersion of mates, prey, and other habitat features. Human activities that further disperse or alter these resources may have the net effect of increasing the area needed by females to sequester sufficient resources. Alteration of the landscape may also increase the distances between female home ranges, which would increase the size of male home ranges. These two changes may result in a decrease in density of Fishers. The large size and wide dispersion of home ranges make Fishers extremely vulnerable to harvest (i.e., trapping) and to changes in habitat suitability through industrial activities such as forestry, mining, and hydroelectric development.

\section{Acknowledgments}

This research was supported by different agencies in each study area. The Beaver Valley study was funded by the Fur Initiatives and Habitat Conservation Fund programs of the British Columbia Ministry of Environment, Lands and Parks; the Habitat Silviculture Protection Account of the British Columbia Ministry of Forests; the British Columbia Trappers Association; and the Science Council of British Columbia. Thanks to R. Wright for project administration. The Williston study was funded by the Peace/Williston Fish 


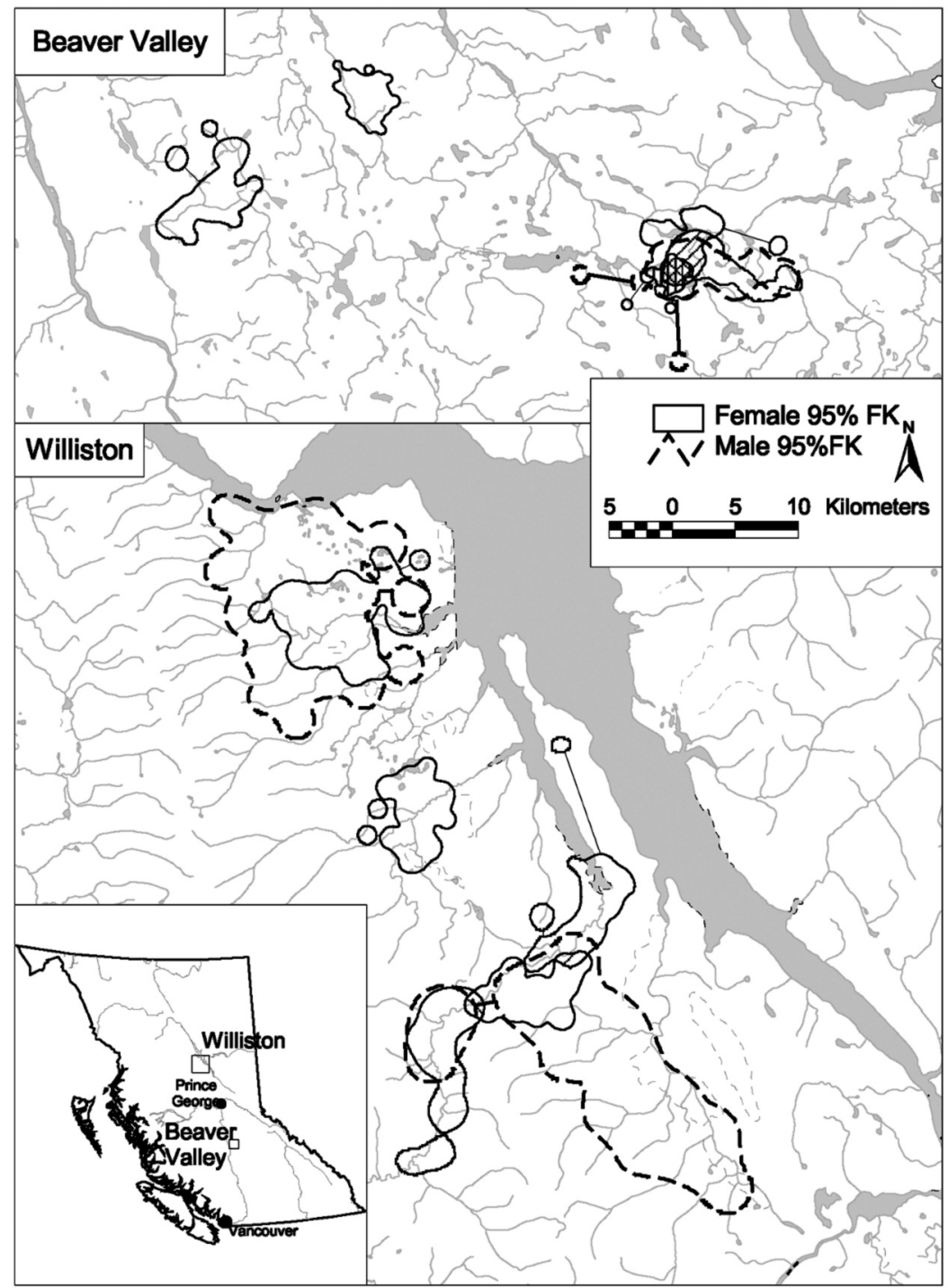

FIGURE 1. Spatial organization of aggregate $95 \%$ utilization distribution home ranges of radiotagged Fishers in the Beaver Valley (1990-1993) and Williston (1996-2000) study areas. Identification numbers that begin with "F" are female Fishers, whereas "M" are males. Discontinuous portions of an individual's home range are connected with black lines.

and Wildlife Compensation Program (a joint initiative of BC Hydro and the BC Ministry of Environment) and Forest Renewal British Columbia. The Ministry of Environment, Slocan Group (Mackenzie Operations), Abitibi Consolidated Ltd., and the British Columbia Trapper's Association provided additional logistical support. We are indebted to A. Bowser, S. Bowsfield, H. Davis, J. Faulkner, V. Hawkes, E. Lofroth, J. McCormick, J. Steciw, A. Stewart, K. Webster, and $\mathrm{R}$. Wright for their invaluable assistance. This manu- script was improved by comments from R. Truex and several anonymous reviewers.

\section{Literature Cited}

Arthur, S. M., W. B. Krohn, and J. R. Gilbert. 1989. Home range characteristics of adult fishers. Journal of Wildlife Management 53: 674-679.

Badry, M. J., G. Proulx, and P. M. Woodward. 1997. Home-range and habitat use by fishers translocated to the aspen parkland of Alberta. Pages 233-251 in Martes: Taxonomy, ecology, techniques, and management. Edited by 
G. Proulx, H. N. Bryant, and P. M. Woodward. Provincial Museum of Alberta. Edmonton, Alberta, Canada.

Banci, V. 1989. A fisher management strategy for British Columbia. British Columbia Ministry of Environment, Wildlife Branch. Wildlife Bulletin B-63. Victoria, British Columbia, Canada.

British Columbia Ministry of Forests, and British Columbia Ministry of Environment, Lands and Parks. 1995. Biodiversity guidebook. Province of British Columbia. Victoria, British Columbia, Canada.

Buskirk, S. W., and L. L. McDonald. 1989. Analysis of variability in home-range size of the American marten. Journal of Wildlife Management 53: 997-1004.

Fuller, T. K., E. C. York, S. M. Powell, T. A. Decker, and R. M. DeGraaf. 2001. An evaluation of territory mapping to estimate fisher density. Canadian Journal of Zoology 79: 1691-1696.

Garant, Y., and M. Crête. 1997. Fisher, Martes pennanti, home range characteristics in a high density untrapped population in southern Québec. Canadian Field-Naturalist 111: 359-364.

Harestad, A. S., and F. L. Bunnell. 1979. Home range and body weight - a reevaluation. Ecology 80: 389-402.

Heinemeyer, K. S. 1993. Temporal dynamics in the movements, habitat use, activity, and spacing of reintroduced fishers in northwestern Montana. Thesis, University of Montana, Missoula, Montana, USA.

Hooge, P. N., and B. Eichenlaub. 1999. Animal movement extension to ArcView, version 2.04. Alaska Biological Sciences Center, US Geological Survey, Anchorage, Alaska, USA.

Jones, J. L. 1991. Habitat use of fisher in northcentral Idaho. Thesis, University of Idaho, Moscow, Idaho, USA.

Kelly, G. M. 1977. Fisher (Martes pennanti) biology in the White Mountain National Forest and adjacent areas. Dissertation, University of Massachusetts, Amherst, Massachusetts, USA.

Koen, E. L., J. Bowman, C. S. Findlay, and L. Zheng. 2007. Home range and population density of fishers in eastern Ontario. Journal of Wildlife Management 71: 1484-1493.

MacKinnon, A., C. DeLong, and D. Meidinger. 1990. A field guide for identification and interpretation of ecosystems of the northwest portion of the Prince George Forest Region. British Columbia Ministry of Forests. Land Management Handbook number 21. Victoria, British Columbia, Canada.

Meidinger, D. V., J. Pojar, and W. L. Harper. 1991. Chapter 14: Sub-boreal spruce zone. Pages 209-221 in Ecosystems of British Columbia. Edited by D. V. Meidinger and J. Pojar. Special Report Service Number 6. British Columbia Ministry of Forests, Research Branch, Victoria, British Columbia, Canada.
Moors, P. J. 1980. Sexual dimorphism in the body size of mustelids (Carnivora): The roles of food habits and breeding systems. Oikos 34: 147-158.

Nams, V. O. 1990. Locate II triangulation software. Pacer Software, Truro, Nova Scotia, Canada.

Powell, R. A. 1979. Mustelid spacing patterns: Variations on a theme by Mustela. Zeitschrift für Tierpsychologie 50: 153-165.

Powell, R. A. 1993. The fisher: Life history, ecology, and behavior. Second edition. University of Minnesota Press, Minneapolis, Minnesota, USA.

Powell, R. A. 1994. Structure and spacing of Martes populations. Pages 101-121 in Martens, sables, and fishers: Biology and conservation. Edited by S. W. Buskirk, A. S. Harestad, M. G. Raphael, and R. A. Powell. Cornell University Press, Ithaca, Ithaca, New York, USA.

Seaman, D. E., J. J. Millspaugh, B. J. Kernohan, G. C. Brundige, K. J. Raedeke, and R. A. Gitzen. 1999. Effects of sample size on kernel home range estimates. Journal of Wildlife Management 63: 739-747.

Steen, O. A., and R. A. Coupé. 1997. A field guide to forest site identification and interpretation for the Cariboo Forest Region. A field guide to forest site identification and interpretation for the Cariboo Forest Region. British Columbia Ministry of Forests. Land Management Handbook 39. Victoria, British Columbia, Canada.

Strickland, M. A., C. W. Douglas, M. K. Brown, and G. R. Parsons. 1982. Determining the age of fisher from cementum annuli of the teeth. New York Fish and Game Journal 29: 90-94.

Thompson, I. D., and P. W. Colgan. 1987. Numerical responses of martens to a food shortage in northcentral Ontario. Journal of Wildlife Management 51: 824-835.

Weir, R. D. 1995. Diet, spatial organization, and habitat relationships of fishers in south-central British Columbia. Thesis, Simon Fraser University, Burnaby, British Columbia, Canada.

Weir, R. D., and F. B. Corbould. 2006. Density of fishers in the Sub-boreal Spruce biogeoclimatic zone of British Columbia. Northwestern Naturalist 87: 118-127.

Weir, R. D., and A. S. Harestad. 2003. Scale-dependent habitat selectivity by fishers in south-central British Columbia. Journal of Wildlife Management 67: 73-82.

White, G. C., and R. A. Garrott. 1990. Analysis of Wildlife Radio-tracking Data. Academic Press, San Diego, California, USA.

Worton, B. J. 1989. Kernel methods for estimating the utilization distribution in home-range studies. Ecology 70 : 164-168.

Received 2 January 2009

Accepted 13 January 2010 